\title{
Winter Latitudinal Population Age-Structure of a Migratory Seagull (Larus fuscus) Differs between Its Two Major Migratory Flyways
}

\author{
Paulo A. M. Marques ${ }^{1,2}$ and Paulo E. Jorge ${ }^{1,3}$ \\ ${ }^{1}$ Unidade de Investigação em Eco-Etologia, ISPA, Instituto Universitário, R. Jardim Tabaco, 1149-041 Lisboa, Portugal \\ ${ }^{2}$ Museu Nacional de História Natural e da Ciência, Universidade de Lisboa, Rua da Escola Politécnica, 58, 1250-102 Lisboa, Portugal \\ ${ }^{3}$ Biological Sciences Department, Virginia Tech, 800 Drillfield Dr, Blacksburg, VA 24061, USA \\ Correspondence should be addressed to Paulo A. M. Marques; pamarques@ispa.pt
}

Received 19 July 2013; Accepted 1 November 2013

Academic Editor: Jean-Guy Godin

Copyright (C) 2013 P. A. M. Marques and P. E. Jorge. This is an open access article distributed under the Creative Commons Attribution License, which permits unrestricted use, distribution, and reproduction in any medium, provided the original work is properly cited.

\begin{abstract}
The migration is energy-demanding and is expected to greatly affect the distribution of individuals over the species range and condition the choice of migratory routes. We investigated the wintering distributions and migratory flyways use of geographically contiguous populations of Lesser Black-backed Gulls (Larus fuscus) and difference in population winter age structure between migratory flyways. Recoveries of metal ringed pulli from Denmark, Sweden, and Finland were used. The results showed that contiguous populations can have distinct wintering distribution patterns and migratory flyways. More importantly, we found that depending on the place of origin, the population winter distribution may or may not show a latitudinal cline in the age structure. The population migrating via the eastern Atlantic flyway (western flyway) showed a winter age-related latitudinal cline, with adults staying at more northern latitudes than immatures. In contrast, no such pattern was found in the population migrating along the Mediterranean/Black sea flyway (eastern flyway). Interestingly, immatures within the eastern population showed a more dispersed pattern of migratory bearings. Overall, our results enhance the importance of the migration flyway in shaping the age structure of populations in the winter quarters and how it may influence the effect of other factors like sexual maturation.
\end{abstract}

\section{Introduction}

During migration, geographically distinct populations of the same species can face different challenges when moving between breeding and wintering areas. Ecological barriers, such as the Sahara Desert, or mountain ranges, such as the Alps or the Pyrenees, contribute to the shaping of migratory routes and the patterns of distribution of the species that have to cross them $[1,2]$. Thus, in species that are spread over wide geographical ranges, populations from the extremes of the distribution can have different migratory problems to solve and can thus develop distinct migratory behaviours in response to the specific ecological constraints (e.g., different migratory routes or migration timings [3-5]).

A longitudinal effect on the wintering distribution of populations has been well documented [6-9]; birds that breed furthest west in the breeding range tend to winter furthest west in the nonbreeding range, while those that breed furthest east also winter furthest east. This pattern represents a general tendency revealed by ringing recovery data for most groups of birds $[1,2]$. Similarly, latitudinal effects can also be found within and among populations of the same species $[10,11]$. Within-population results evidence the existence of a variety of distribution and differential migration patterns [12]. Differential patterns that may be related to sex [13], age $[14,15]$, or a combination of both [16].

Because age affects the behaviour of individuals, it is an important factor to consider when analyzing the geographic distribution patterns of populations [12, 17]. In a western population of Lesser Black-backed Gulls, Larus fuscus, adults, and juveniles were shown to exhibit different migration habits and distribution patterns $[18,19]$, with adults staying in the 

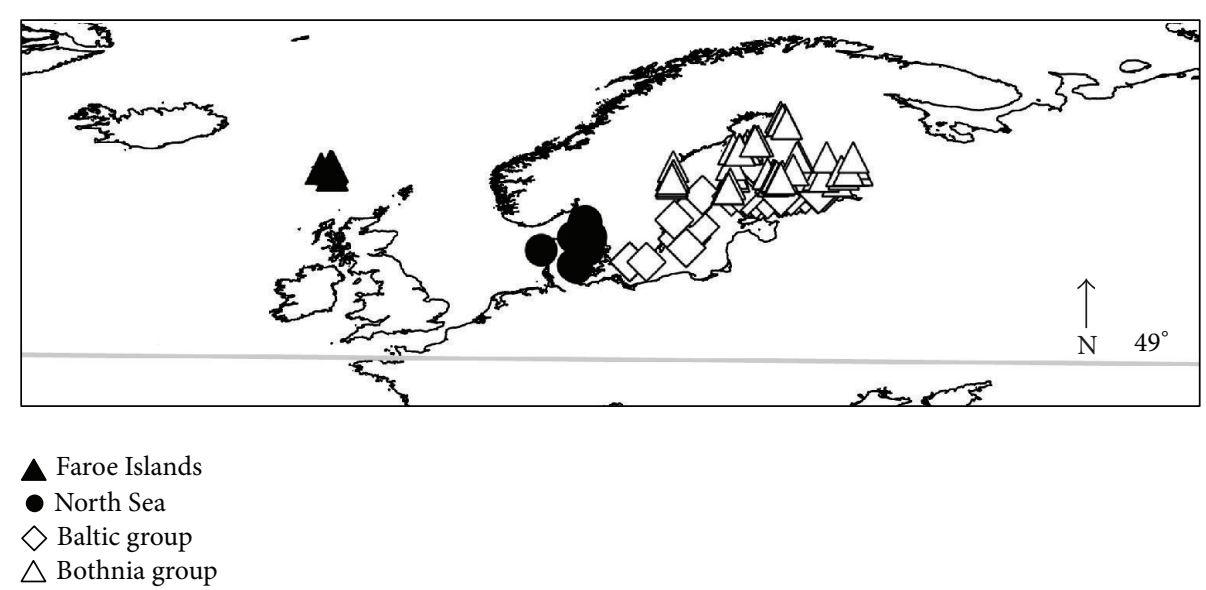

FIGURE 1: Breeding areas of Larus fuscus populations and distribution of ringing places at Faroe Islands, Danish and Swedish North Sea, Baltic Sea and Gulf of Bothnia, and Finnish mainland.

northern part of the distribution range while juveniles stayed further south. Thus, in order to understand the migration and distribution patterns over the species range, it is essential to consider both the effects of ecological constraints (e.g., ecological barriers) and the individual's behavioural constraints (e.g., sexual maturation).

In this study we analyzed the wintering distributions of populations of Lesser Black-backed Gulls breeding in the northern breeding range of the species, (Sweden, Denmark, and Finland, Figure 1). The species uses two major migration flyways, a eastern Atlantic flyway (western flyway), and a Mediterranean/Black sea flyway (eastern flyway) [20, 21]. According to the parallel migration pattern (see above) we expect that populations will differ in their longitudinal winter distributions depending on their breeding location. In addition, we will expect a latitudinal population age-structure variation in the two migration flyways with adults staying more northern than juveniles in the winter range. Here, we investigate the migration and wintering patterns in several northern breeding populations (Figure 1). We predicted that if sexual maturation is in the onset of age related distribution patterns, then northern populations of L. fuscus should all present similar distribution patterns in the wintering area.

\section{Methods}

2.1. Species and Study Area. The Lesser Black-backed Gull L. fuscus is a migratory species with a wide distribution. Its breeding area extends across the coastal areas of Europe and Asia, from Iceland to France and to Russia, while its wintering range extends from Europe, to the Black Sea, and Africa.

2.2. Dataset and Subpopulations. This study used data from the Danish ringing centre at the Natural History Museum of Denmark (SNM), the Swedish ringing centre at the Swedish Museum of Natural History (NRM), and the Finnish ringing centre at the Finnish Museum of Natural History (FMNH). From the overall set of data (all based on metal ring recoveries) we only extracted records of gulls ringed as pulli that had species verification, accuracy of date higher than 6 weeks (i.e., date of finding death $\leq 6$ weeks), and accuracy of place higher than $2.5 \mathrm{~km}$ radius (i.e., radius $\leq 2.5 \mathrm{~km}$ ). We excluded all records of birds found not freshly dead or with condition unknown or not ringed as pulli. In addition, we used recoveries of gulls during the winter period from November to February and found at least $500 \mathrm{~km}$ away from their ringing place. This perimeter allowed avoids potential biases on recovery data. These criteria ensure the taxonomical, temporal, and spatial data quality level necessary to this study. A total of 229 recoveries matched all the above criteria.

Based on migration atlases $[20,21]$, the dataset was divided into two populations according to their ringing location: a western population ringed in the Faroe Islands and the North Sea (mainland Denmark and west coast of Sweden) and an eastern population ringed in the Baltic Sea, the Gulf of Bothnia, and mainland Finland (Figure 1). The wintering distributions of individuals were studied based on division of the wintering range into three areas: the area above parallel $49^{\circ}$ (north), the area between parallels $49^{\circ}$ (central) and $30^{\circ}$ (south), and areas bellow parallel $30^{\circ}$, corresponding to areas north of the Alps and Carpathian mountains, between these and the Sahara Desert, and south of the Sahara Desert (Figure 2).

2.3. Age Structure. Individuals were classified into two age classes according to their age at the time of recovery: immature (1st and 2nd winters) and adults (3rd or more winters). Data were analyzed using contingency tables. Hypotheses were analyzed using a simulation program that performs the $\chi^{2}$ test (ACTUS software). ACTUS allowed us to assess the significance of the contingency table without normal restrictions imposed by the simple use of the $\chi^{2}$ test, whilst allowing simultaneous assessment of the significance of the deviations between expected and observed frequencies of individual cells based on 1,000 simulations (for details see $[14,22])$. In addition, an ANOVA approach was used to test the hypotheses about longitudinal population differences (two-factor ANOVA, longitude was used as the dependent 


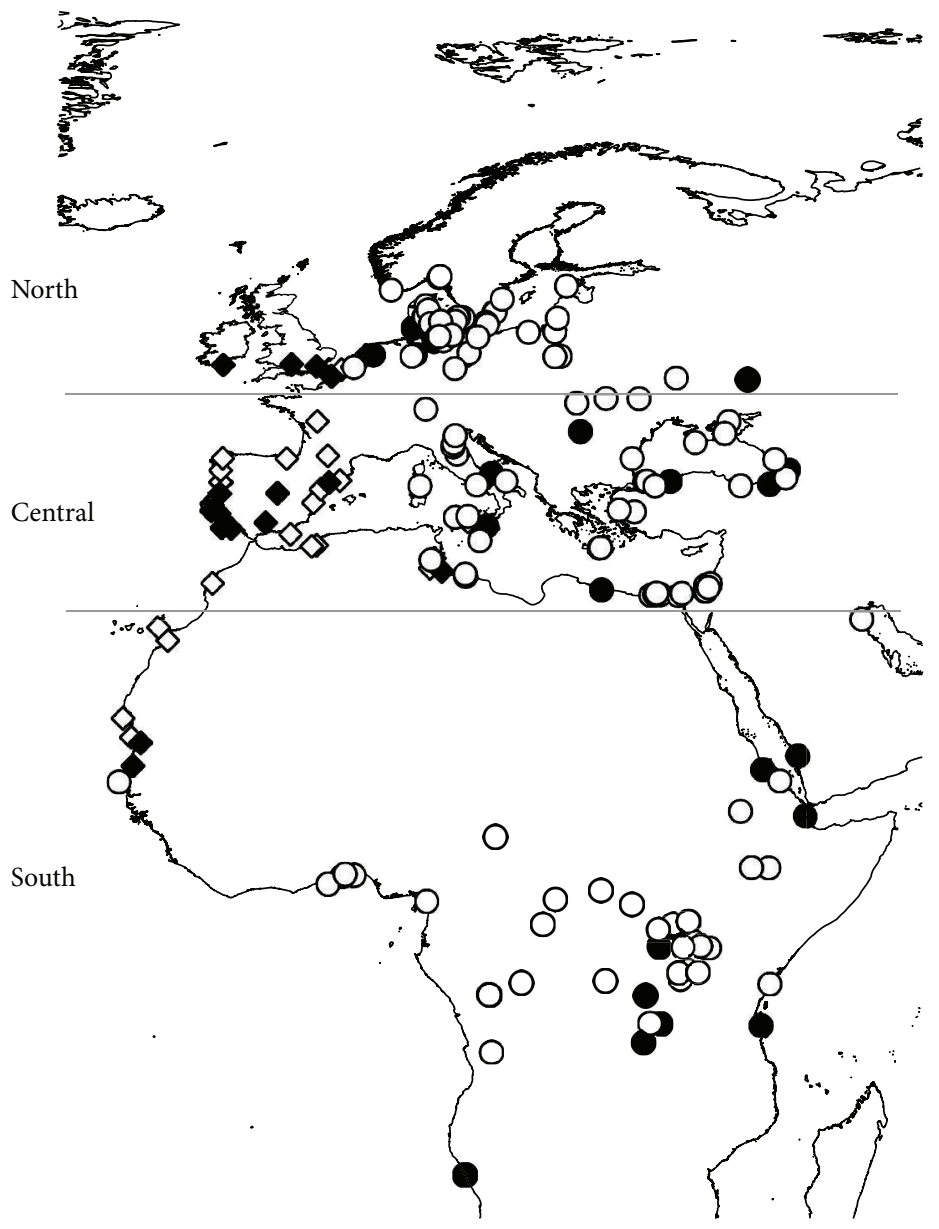

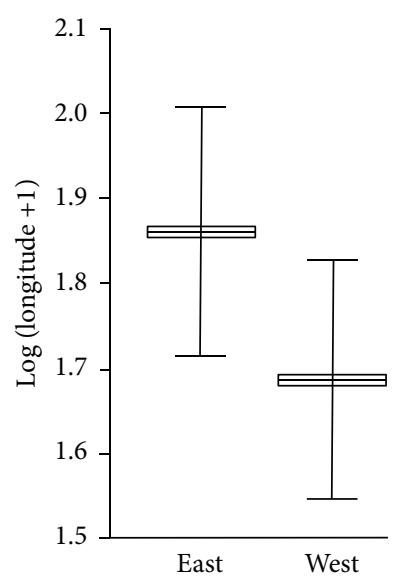

(a)

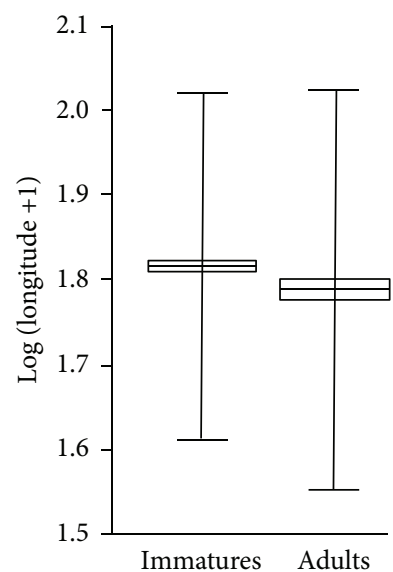

(b)

FIGURE 2: Effect of age and population origin in the winter longitudinal distribution of Larus fuscus: (a) population effect, west and east populations longitudinal distribution (log (longitude +1$)$ ) and (b) age effect, immature and adults longitudinal distribution (log (longitude $+1)$ ); line: mean, box: standard error of the mean, and whiskers: standard deviation.

variable and population and age as independent factors) and to compare the distances travelled by adults to the wintering areas (one-factor ANOVA, distance was used as the dependent variable and population as the independent factor). Because, variables "longitude" and "distance" were not uniform, logarithmic transformations were applied $(\log (x+$ 1)).

2.4. Migratory Bearings. Distances between pairs of observations were calculated from the geographic coordinates using the orthodromic distance, which represents the distance between two points along a spherical surface. The orthodromic distance $(l)$ was calculated using the following expression:

$$
\text { (a) } \begin{aligned}
l=\operatorname{acos}( & \sin (\text { lat } 1) \times \sin (\text { lat } 2)+\cos (\text { lat } 1) \\
& \times \cos (\text { lat } 2) \times \cos (\text { lon } 2-\operatorname{lon} 1)) \times r,
\end{aligned}
$$

where latl represents the latitudinal coordinate of location 1 , long1 the longitudinal coordinate of location 1, lat 2 the latitudinal coordinate of location 2 , and long2 the longitudinal coordinate of location 2, and $r$ is the radius of the earth $(r=6371 \mathrm{~km})$ [23].

Migratory bearings were calculated using the following formula:

$$
\begin{aligned}
(b)=\operatorname{atan} 2( & \sin (\text { lon } 2-\text { lon } 1) \times \cos (\text { lat } 2), \\
& \cos (\text { lat } 1) \times \sin (\text { lat } 2)-\sin (\text { lat } 1) \\
& \times \cos (\text { lat } 2) \times \cos (\text { lon } 2-\text { lon } 1)) .
\end{aligned}
$$

Bearings calculated using (b) were then grouped by populations and within populations by age classes and analyzed using software for circular statistics (Oriana 2). The significance of each mean vector ( $\alpha$, mean angular direction; $r$, mean vector length) was given by the Rayleigh test.

\section{Results}

3.1. Interpopulation Distribution. The studied populations of Lesser Black-backed Gulls wintered along the European 


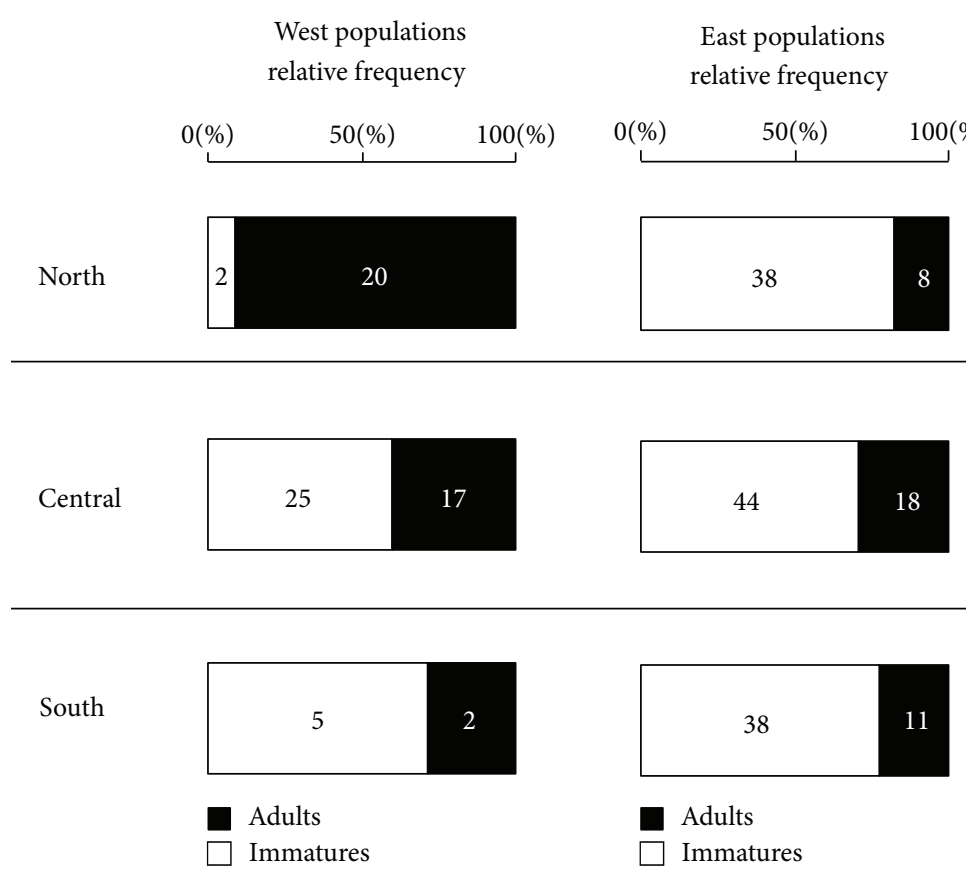

FIGURE 3: Age-related distribution of Larus fuscus in winter range. Age structure of the gulls (as the relative frequency of the immatures $(0$ and 1 year-old) and adults $\left(2\right.$ or more year-old)) at the North (above $49^{\circ}$ ), Central (between $49^{\circ}$ and $30^{\circ}$ ), and South areas (bellow $30^{\circ}$ ). Numbers inside bars correspond to dead birds recovered in each class.

and African Atlantic coasts (i.e., from The Netherlands to Portugal and from Morocco to Namibia), in the Mediterranean and Red Seas and in Central Africa (Figure 2(a)). The two populations analyzed were not uniformly distributed across the wintering area (ANOVA population $F_{1,225}=$ 297.33, $P<0.0001$ ), with populations having wintering ranges that reflected their positioning within the breeding areas (Figure 2(b)). We also found an effect of age in longitude with adults overall stay more to west (ANOVA age $F_{1,225}=$ 6.07, $P<0.01$; Figure 2(c)) but no significant interaction between age and population (ANOVA population $\times$ age $\left.F_{1,225}=1.45, P=0.229\right)$. The western population wintered along the European and African Atlantic coasts and in the western part of the Mediterranean Sea, while the eastern population wintered in the eastern part of the Mediterranean Sea, in the Red Sea and in Central Africa.

3.2. Intrapopulation Distribution. The age-related distributions of the different populations across their wintering ranges differed (Figures 2 and 3 ). The western population showed an age-related latitudinal cline $\left(\chi^{2}=17.012, n=72\right.$, $\mathrm{df}=2$, and $P<0.001$; Figure 3 ) with a significant north-tosouth decrease in the relative abundance of adults (simulation test, $P<0.05)$ and an increase in the relative abundance of immatures (simulation test, $P<0.05$ ). In contrast, the age structure in the eastern population remained uniform across the latitudinal cline $\left(\chi^{2}=2.036, n=157\right.$, and $\mathrm{df}=2, P>0.3$; Figure 3$)$. Interestingly, the distribution of individuals from the two populations differ significantly (adults: $\chi^{2}=11.36, n=76, \mathrm{df}=2$, and $P<0.01$; juveniles: $\chi^{2}=18.07, n=152, \mathrm{df}=2, P<0.001$; Figure 3 ).
Moreover, adults from each population differed in the distance travelled to the wintering areas (ANOVA $F_{1,75}=$ 20.98, $P<0.0001$ ), with eastern adults travelling almost twice as far as western adults (eastern adults: mean distance travelled, $3737 \mathrm{~km}$; western adults: mean distance travelled $1789 \mathrm{~km})$.

3.3. Interpopulation Migratory Bearings. Because the eastern and western populations breed and winter in geographically distinct areas, we analyzed the bearings of their migratory flights. As expected, the western population showed a significant south-southwestward orientation, while the eastern population showed a significant southward orientation (Figure 4), and these migratory orientations differed significantly between the two populations (Figure 4).

3.4. Intrapopulation Migratory Bearings. Analysis of each population by age class (adults versus immatures) showed no difference between the preferred migratory directions of adults and immatures in the western population (Figure 4); however, in the eastern population, the preferred directions of immatures and adults were significantly different, with adults migrating along a direction slightly east of south and immatures along a direction slightly west of south (Figure 4).

\section{Discussion}

Birds heading south during their fall migration generally tend to follow parallel routes, with populations breeding further west also wintering further west, and similarly for populations in the east $[1,2]$. As previously known L. fuscus 


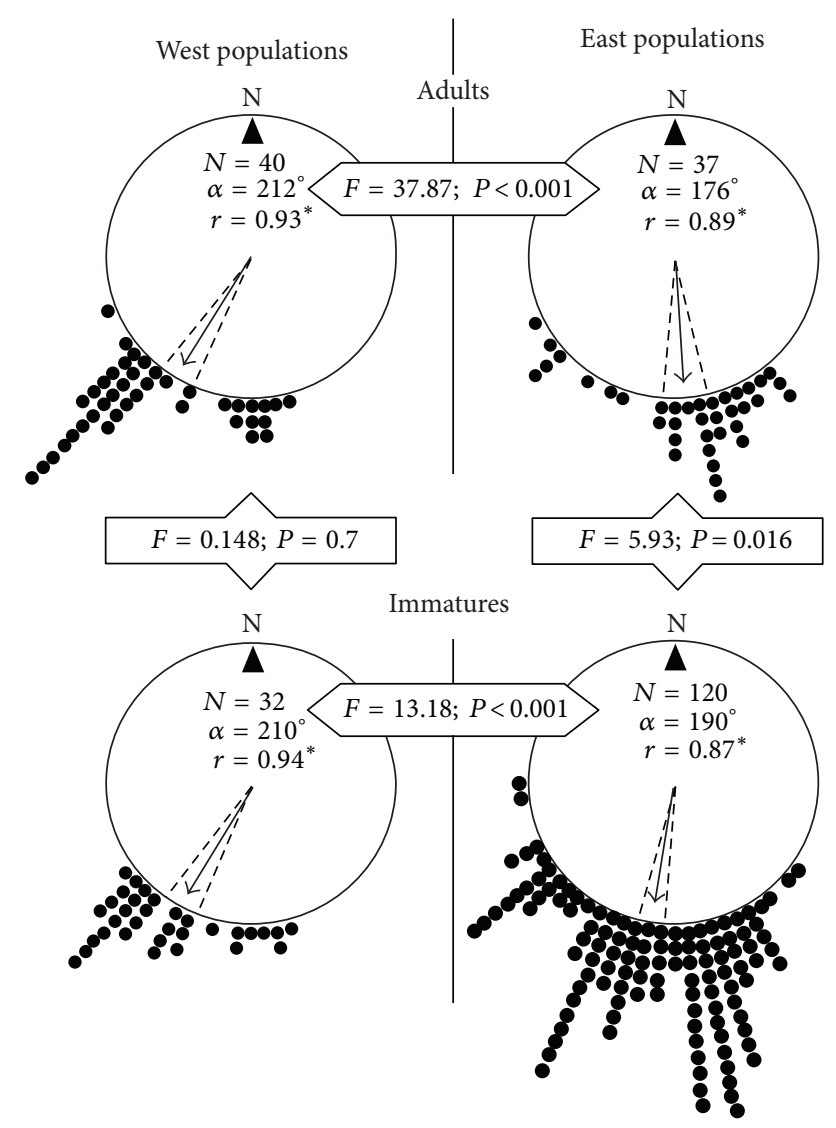

FIGURE 4: Directions of adults and immatures winter locations relative to the ringing place for west and east populations. $\mathrm{N}$ sample size, $\alpha$-vector direction, $r$-vector length. Significance of the vanishing bearings is given by the Rayleigh according to ${ }^{*} P<0.001$.

is no exception $[20,21]$; populations breeding west tend to be distributed to the west of the wintering range, while populations breeding east tend to be distributed to the east of the wintering range. This tendency corresponds to a longitudinal cline in accordance with a parallel migration pattern, but with an overlap in the central Mediterranean area (Figure 2).

Adults and immatures of several species exhibit different migration patterns [12], potentially resulting in an age-related latitudinal cline over the species' wintering range (e.g., [24]). Previously, it was reported for a L. fuscus western population that adults tend to stay in the northern parts of the wintering range, while immatures distribute further south $[18,19]$. The findings were then interpreted in light of the arrival time hypothesis [18]. In accordance, our western population followed an age-related cline across the wintering range, but the eastern population followed a distinct pattern, with individuals distributed homogeneously across the population's wintering range, regardless of their age (Figure 3 ). The difference between wintering distributions importantly suggests that the two groups are facing different ecological constraints (e.g., presence/absence of stopovers or presence/absence of ecological barriers). Alternatively, one can hypothesized that recovery biases are behind the observed results. However, a careful selection and standardization of the data analysed (see methods), in addition to the lines of evidence that in the eastern flyway the number of recoveries is not affected with latitude (i.e., in areas that theoretically could be problematic due to lower population density; Figure 3), disclosed recovery biases from playing a rule in the observed results. The question appears to be more complex and findings suggest that the two populations are facing different constraints during migration. Western populations can freely migrate southward along the Atlantic Coast, while eastern populations have to cross two important ecological barriers: the Alps and the Sahara desert. Consequently, gulls flying via the eastern flyway have to travel significantly greater distances than gulls flying via the western flyway, for wintering (Figure 2). The consequences of this effort are unknown, but the ongoing complex dynamics in the breeding areas of the eastern population (with local decreasing populations, food shortage, disease, and predation, $[25,26])$ suggest that might have an impact in eastern seagulls survival.

Overall, this result suggests that other factor besides age (here as an approach for sexual maturation) may influence the population distribution and, contrary to previously proposed [19], the arrival time hypothesis might not be the best suitable framework to explain the species migration pattern. The presence of a latitudinal cline in the winter population agestructure in the western flyway and its absence in the eastern flyway suggest that besides the sexual maturation, features of the migratory flyway (e.g., food and stopover availability or ecological barriers) are important in shaping migration patterns.

Parallel migration theoretically suggests that populations should follow the same vector bearings when migrating between the breeding and wintering areas. However that is not necessarily what occurs, and even when a population's wintering distribution mirrors that of their breeding distribution, they may have to follow distinct migratory bearings. Because of the different winter distributions we would expect the eastern L. fuscus population to follow a different migratory bearing from that followed by the western population. Indeed, our results showed that the eastern and western populations differed in terms of their migratory bearings (Figure 4), with the western population following a southwestward bearing, similar to other western populations, along the Atlantic European coast [27, 28], while the eastern population followed a southward bearing across central Europe (Figure 4). Surprisingly, adults and immatures in the eastern population followed different migration directions (Figure 4). More detailed analysis showed that eastern immatures actually had two migration directions, with a fraction of the population presenting a general migratory bearing southwestward similar to the migratory bearing of immature of the western population and another southward similar to the migratory bearing of adults of their own population (Figure 4). In a recent study with a Norwegian population of L. fuscus, which was expected to migrate via the eastern flyway also found that a portion of 1st winters migrate via the western flyway [26]. In contrast, adults migrate via the eastern flyway [26].

The pattern of migratory bearings seen in the eastern population raises several interesting questions. In many 
species the juveniles use an innate spatiotemporal migratory program [29]. However, since adults have a different bearing, adults must have learnt to use an alternative migratory route. Therefore, our results can be explained by immatures either migrating alone or with adults, adult guiding to use the eastern flyway. Immatures (e.g., first-winter migrants) are also known to have a tendency to follow older birds during migration, thus avoiding naïve navigational errors (e.g., [30]). We know that gulls can change their migratory behaviour with age [18] and this result could be due to a similar process. The orography of the Baltic Sea area provides a natural trap, keeping a fraction of immatures in this region until severe winter weather results in their death and potentiating the use of the eastern flyway. The longer migration distances of the eastern adult gulls and the two alternative migration directions of the immature (see above), combined with other factors such as food shortages and pollution [25, 31], could be influencing the decline of the eastern populations by affecting offspring quality and timing of migration.

Overall, we identified two different patterns of migration and wintering habits in two geographically contiguous populations within the same species. These results reinforce the role of flyway characteristics, like ecological barriers and stopover availability, in shaping population winter age structure and thus migration routes and annual routines. Understanding this interaction is of fundamental importance to identify important processes with potential implications for conservation plans (e.g., [25, 32], population control (e.g., [33]), and/or the evaluation of human health risks (e.g., dissemination of contagious diseases (e.g., [34]).

\section{Conflict of Interests}

The authors declare that there is no conflict of interests regarding the publication of this paper.

\section{Acknowledgments}

The authors wish to thank K. Thorup, K. J. Pedersen and J. Madsen at SNM/DK, Thord Fransson at NRM/SW, and Jari Valkama at FMNH/FI for help and data. PAMM was supported by Grant SFRH/BPD/34846/2007 and PEJ by Grant SFRH/BPD/64087/2009 both from the Portuguese Science Foundation (FCT). This project was partially financed by Synthesys under DK-TAF 808 visit to SNM/DK. The experiments comply with the current laws of the countries in which they were performed.

\section{References}

[1] R. E. Moreau, The Palearctic-African Bird Migration System, Academic Press, London, UK, 1972.

[2] I. Newton, The Migration Ecology of Birds, Academic Press, London, UK, 2008.

[3] S. Bauer, B. J. Ens, and M. Klaassen, "Many routes lead to Rome: potential causes for the multi-route migration system of Red Knots, Calidris canutus islandica," Ecology, vol. 91, no. 6, pp. 1822-1831, 2010.
[4] J. Shamoun-Baranes and H. van Gasteren, "Atmospheric conditions facilitate mass migration events across the North Sea," Animal Behaviour, vol. 81, no. 4, pp. 691-704, 2011.

[5] P. Pinet, S. Jaquemet, D. Pinaud, H. Weimerskirch, R. A. Phillips, and M. Le Corre, "Migration, wintering distribution and habitat use of an endangered tropical seabird, Barau's petrel Pterodroma baraui," Marine Ecology Progress Series, vol. 423, pp. 291-302, 2011.

[6] P. Berthold, A. J. Helbig, G. Mohr, and U. Querner, "Rapid microevolution of migratory behaviour in a wild bird species," Nature, vol. 360, no. 6405, pp. 668-670, 1992.

[7] P. Berthold and U. Querner, "Genetic basis of migratory behavior in European warblers," Science, vol. 212, no. 4490, pp. 77-79, 1981.

[8] V. Bingman, C. Budzynski, and A. Voggenhuber, "Migratory systems as adaptive responses to spatial and temporal variability in orientation stimuli," in Avian Migration, P. Berthold, E. Gwinner, and E. Sonnenschein, Eds., pp. 567-469, Springer, Berlin, Germany, 2003.

[9] A. J. Helbig, "Inheritance of migratory direction in a bird species: a cross-breeding experiment with SE- and SWmigrating blackcaps (Sylvia atricapilla)," Behavioral Ecology and Sociobiology, vol. 28, no. 1, pp. 9-12, 1991.

[10] W. A. Boyle, "Partial migration in birds: tests of three hypotheses in a tropical lekking frugivore," Journal of Animal Ecology, vol. 77, no. 6, pp. 1122-1128, 2008.

[11] J. M. Boland, "Leapfrog migration in north american shorebirds: intra- and interspecific examples," Condor, vol. 92, pp. 284-290, 1990.

[12] D. A. Cristol, B. M. Baker, and C. Carbone, "Differential migration revisited: latitudinal segregation by age and sex class," Current Ornithology, vol. 15, pp. 33-88, 1999.

[13] K. J. Mathot, B. D. Smith, and R. W. Elner, "Latitudinal clines in food distribution correlate with differential migration in the Western Sandpiper," Ecology, vol. 88, no. 3, pp. 781-791, 2007.

[14] P. A. M. Marques, A. M. Costa, P. Rock, and P. E. Jorge, "Agerelated migration patterns in Larus fuscus spp," Acta Ethologica, vol. 12, no. 2, pp. 87-92, 2009.

[15] J. Gromadzka and L. Serra, "Differential migration of juvenile and adult Grey Plovers Pluvialis squatarola at the mouth of the Vistula River, Poland," Ornis Fennica, vol. 75, no. 4, pp. 193-199, 1998.

[16] P. Catry, A. Campos, V. Almada, and W. Cresswell, "Winter segregation of migrant European robins Erithacus rubecula in relation to sex, age and size," Journal of Avian Biology, vol. 35, no. 3, pp. 204-209, 2004.

[17] E. D. Ketterson and V. Nolan Jr., "The evolution of differential bird migration," Current Ornithology, vol. 1, pp. 357-402, 1983.

[18] P. A. M. Marques, D. Sowter, and P. E. Jorge, "Gulls can change their migratory behavior during lifetime," Oikos, vol. 119, no. 6, pp. 946-951, 2010.

[19] P. E. Jorge, D. Sowter, and P. A. M. Marques, "Differential annual movement patterns in a migratory species: effects of experience and sexual maturation," PLoS ONE, vol. 6, no. 7, Article ID e22433, 2011.

[20] J. Bonlokke, J. Madsen, K. Thorup, K. T. Pedersen, M. Bjerrum, and C. Rahbek, The Danish Bird Migration Atlas Kobenhavns Universitet, Kobenhavns, 2006.

[21] T. Fransson, H. Osterblom, and S. Hall-Karlsson, Swedish Bird Ringing Atlas Volume 2, Grouses-Woodpeckers, Naturhistoriska Riksmuseet, Stockholm, Sweden, 2008. 
[22] C. B. Estabrook and G. F. Estabrook, "ACTUS: a solution to the problem of analysing sparse contingency tables," Hist Methods, vol. 22, pp. 5-8, 1989.

[23] S. Marshak, Earth: Portrait of a Planet, Norton \& Company, New York, NY, USA, 2001.

[24] R. J. Lopes, F. Hortas, and L. Wennerberg, "Geographical segregation in Dunlin Calidris alpina populations wintering along the East Atlantic migratory flyway-evidence from mitochondrial DNA analysis," Diversity and Distributions, vol. 14, no. 5, pp. 732-741, 2008.

[25] N. Varty and K. Tanner, Background Document for Lesser Black Backed Gull Larus Fuscus Fuscus, OSPAR Commission, 2009.

[26] M. Helberg, G. H. Systad, I. Birkeland, N. H. Lorentzen, and J. O. Bustnes, "Migration patterns of adult and juvenile Lesser Blackbacked Gulls Larus fuscus from northern Norway," Ardea, vol. 97, no. 3, pp. 281-286, 2009.

[27] P. Rock and I. Spence, "Lesser Black-backed gull," in The Migration Atlas: Movements of the Birds of Britain and Ireland, C. V. Wernham, M. P. Toms, J. H. Marchant, J. A. Clark, G. M. Siriwardena, and S. R. Baillie, Eds., pp. 365-368, T. \& A.D. Poyser, London, UK, 2002.

[28] S. Cramp and K. Simmons, Eds., Handbook of the Birds of Europe, the Middle East and North Africa: The Birds of the Western Palearctic, Vol III, 1983.

[29] N. Chernetsov, D. Kishkinev, S. Gashkov, V. Kosarev, and C. V. Bolshakov, "Migratory programme of juvenile pied flycatchers, Ficedula hypoleuca, from Siberia implies a detour around Central Asia," Animal Behaviour, vol. 75, no. 2, pp. 539-545, 2008.

[30] K. Thorup, T. Alerstam, M. Hake, and N. Kjellén, "Bird orientation: compensation for wind drift in migrating raptors is age dependent," Proceedings of the Royal Society B, vol. 270, no. 1 , pp. S8-S11, 2003.

[31] J. O. Bustnes, T. Anker-Nilssen, and S.-H. Lorentsen, "Local and large-scale climatic variables as predictors of the breeding numbers of endangered Lesser Black-backed Gulls on the Norwegian Coast," Journal of Ornithology, vol. 151, no. 1, pp. 1926, 2010.

[32] H. Weimerskirch, S. Åkesson, and D. Pinaud, "Postnatal dispersal of wandering albatrosses Diomedea exulans: implications for the conservation of the species," Journal of Avian Biology, vol. 37, no. 1, pp. 23-28, 2006.

[33] P. Rock, "Urban gulls: problems and solutions," British Birds, vol. 98, no. 7, pp. 338-355, 2005.

[34] J. Bonnedahl, M. Drobni, M. Gauthier-Clerc et al., "Dissemination of Escherichia coli with CTX-M type ESBL between humans and yellow-legged gulls in the south of France," PLoS ONE, vol. 4, no. 6, Article ID e5958, 2009. 

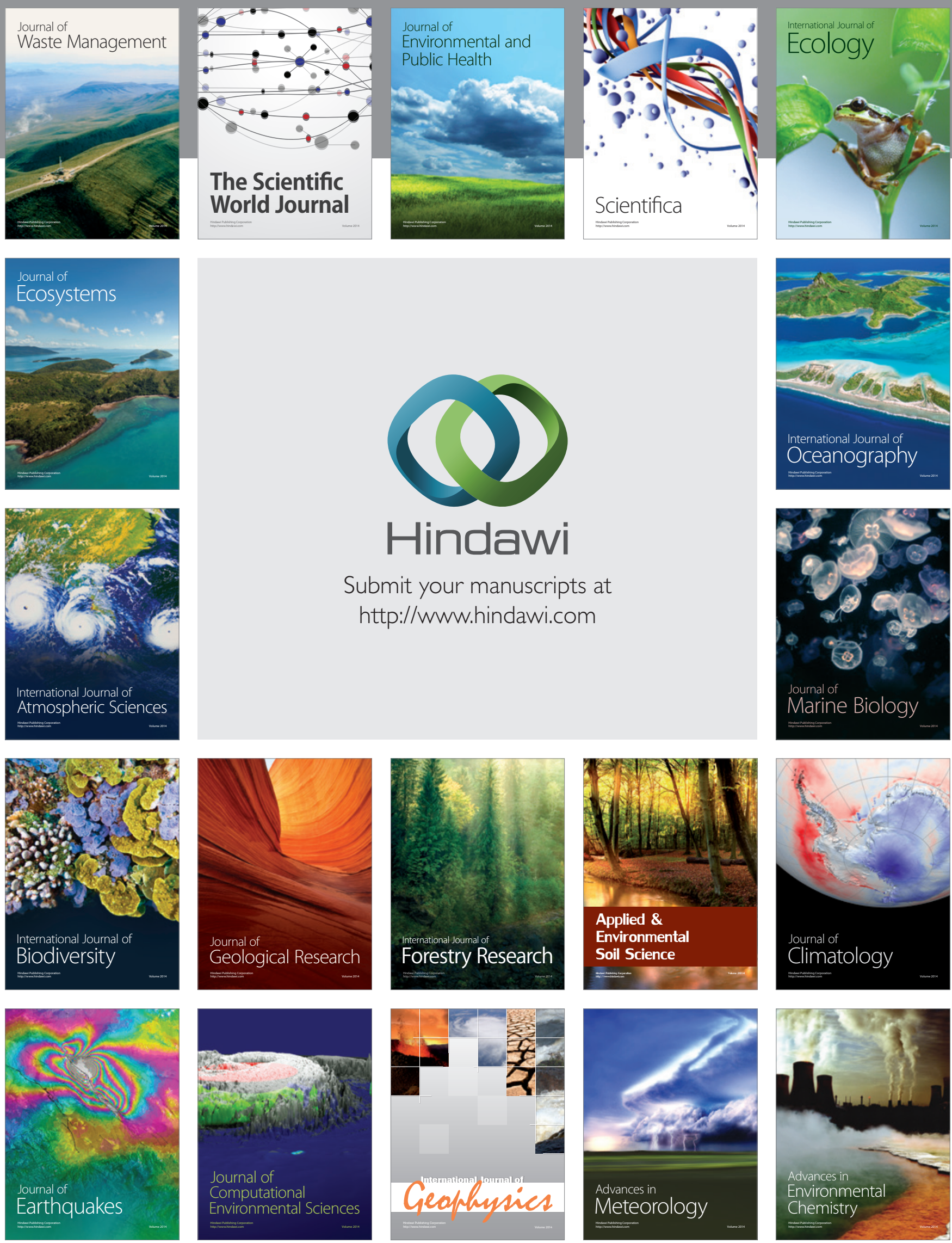